\title{
Avaliação de medidas mitigadoras na atenuação de eventos de inundação na bacia do Botafogo Córrego, Goiânia, GO
}

\author{
Evaluation of mitigating measures in the attenuation of flooding events in the Botafogo Córrego \\ basin, Goiânia, GO \\ Evaluación de medidas de mitigación en la atenuación de eventos de inundación en la cuenca del \\ Botafogo Córrego, Goiânia, GO
}

\begin{abstract}
Resumo
$\mathrm{O}$ processo de adensamento urbano associado às mudanças no perfil das chuvas vem resultando em eventos hidrológicos extremos, gerando situações adversas para as pessoas que vivem ou transitam em áreas de bacias hidrográficas densamente urbanizadas. Neste sentido, objetivou-se propor e avaliar medidas mitigadoras para atenuação dos efeitos decorrentes de chuvas intensas na bacia hidrográfica do córrego Botafogo em Goiânia. Na metodologia adotou-se um cenário de $15 \%$ da área de cada lote destinado ao processo de infiltração e outro que considera a disposição de bacias de retenção nas linhas de fluxo da maior vazão. Considerou-se a relação entre a média das intensidades máximas de precipitação, as condições de cobertura e uso, as características morfométricas da bacia e sua resultante em vazão de pico em face da vazão máxima suportada pelo canal principal. Os resultados indicam que a vazão máxima suportada pelo canal nas proximidades de seu exutório é de $26,51 \mathrm{~m}^{3} / \mathrm{s}$ e que os $15 \%$ de área de cada lote sendo destinados ao processo de infiltração não seriam suficientes para uma atenuação considerável, tendo em vista que resultaria apenas em uma redução de $62,27 \mathrm{~m}^{3} / \mathrm{s}$ para $58,85 \mathrm{~m}^{3} / \mathrm{s}$. Por fim destaca-se que uma das medidas mais recomendadas seria a construção de estruturas de retenção de fluxo nos tributários de maior porte, as quais funcionariam liberando apenas as vazões que, somadas, não ultrapassariam a capacidade do canal principal.
\end{abstract}

Palavras-chave: Bacia hidrográfica; Adensamento urbano; Vazão de pico.

\begin{abstract}
The urban densification process associated with changes in the rain profile has resulted in extreme hydrological events, creating adverse situations for people who live or transit in densely urbanized watershed areas. In this sense, the objective was to propose and evaluate mitigating measures to mitigate the effects of intense rain in the hydrographic basin of the Botafogo stream in Goiânia. In the methodology a scenario was adopted of $15 \%$ of the area of each lot destined for the infiltration process and another that considers the arrangement of retention basins in the flow lines of the highest flow. A relation was considered between the average of the maximum intensities of precipitation, the conditions of coverage and use, the morphometric characteristics of the basin and its resultant in peak flow in face of the maximum flow supported by the main channel. The results indicate that the maximum flow supported by the channel in the vicinity of its outlet is $26.51 \mathrm{~m}^{3} / \mathrm{s}$ and that the $15 \%$ area of each lot being used for the infiltration process would not be sufficient for the considerable attenuation, considering that would only result in a reduction from $62.27 \mathrm{~m}^{3} / \mathrm{s}$ to $58.85 \mathrm{~m}^{3} / \mathrm{s}$. Finally, it is highlighted that one of the most recommended measures would be the construction of retention structures, which would work releasing only the flows that added together would not exceed the capacity of the main channel.
\end{abstract}

Keywords: Hydrographic basin; Urban density; Peak flow. 


\begin{abstract}
Resumen
El proceso de densificación urbana asociado a cambios en el perfil de precipitaciones ha dado lugar a eventos hidrológicos extremos, generando situaciones adversas para las personas que viven o transitan en áreas de cuencas densamente urbanizadas. En este sentido, el objetivo fue proponer y evaluar medidas mitigantes para atenuar los efectos resultantes de las fuertes lluvias en la cuenca hidrográfica del arroyo Botafogo en Goiânia. En la metodología se adoptó un escenario del 15\% del área de cada lote destinado al proceso de infiltración, y otro escenario que considera la disposición de las cuencas de retención en las líneas de flujo de mayor caudal. Se consideró la relación entre el promedio de las intensidades máximas de precipitación, las condiciones de cobertura y uso, las características morfométricas de la cuenca y su resultante en caudal pico frente al caudal máximo soportado por el canal principal. Los resultados indican que el caudal máximo soportado por el canal en las inmediaciones de su desembocadura es de $26,51 \mathrm{~m}^{3} /$ sy que el $15 \%$ de área de cada lote destinado al proceso de infiltración no sería suficiente para una atenuación considerable, considerando que sólo resultaría en una reducción de $62,27 \mathrm{~m}^{3} / \mathrm{sa} 58,85 \mathrm{~m}^{3} / \mathrm{s}$. Finalmente, cabe señalar que una de las medidas más recomendadas sería la construcción de estructuras de retención de flujo en afluentes mayores, que funcionarían liberando solo los flujos que, sumados, no excederían la capacidad del canal principal.
\end{abstract}

Palabras clave: Cuenca hidrográfica; Densificación urbana; Flujo máximo.

\title{
1. Introdução
}

Goiânia surgiu no período caracterizado pela intervenção da Era Vargas nos estados brasileiros, sendo fundada em 1933, com seu plano original elaborado por Attílio Correia Lima e esboçada para atingir apenas 50 mil habitantes (Marques, 2009).

Para Zaraté e Pantaleão (2014), o córrego Botafogo constituiria uma rede de parques lineares. Os córregos e rios eram considerados elementos estruturantes do urbano, por associar o espaço público às pessoas, permitindo mobilidade dos veículos e preservação ambiental, com influência direta no sistema hidrológico da sub-bacia.

Tucci (2012) define que a bacia hidrográfica pode ser considerada como um sistema, onde os volumes de entrada são advindos da precipitação, determinados através de hidrogramas e, os volumes de água escoados através do exutório, representam a saída deste sistema, caracterizada pelos hietogramas (Tucci, 2012).

Gorniack (2014) define a bacia hidrográfica ou de drenagem como área da superfície terrestre que capta a água advinda das precipitações, drenando-a, com sedimentos e materiais nela dissolvidos ou não, para um ponto comum, chamado de exutório. As alterações nos elementos da bacia no decorrer do processo de urbanização podem modificar o percentual de duas variáveis (relação entre infiltração x escoamento superficial) do ciclo hidrológico, a impermeabilização do solo por selagem advinda das edificações, calçadas, acessos, dentre outros.

Os usos e ocupações do solo urbano em bacias hidrográficas estão associados ao crescimento acelerado das cidades, com planejamento incipiente, ocupação desordenada e falhas na infraestrutura do sistema de drenagem urbana, com influência direta na redução da cobertura vegetal e aumento da compactação e impermeabilização do solo.

Quaisquer alterações, seja antrópica ou natural, interferem no sistema hidrológico. Nessa acepção, Soares (2017) expõe que informações sobre o uso do solo são relevantes para políticas de gestão de bacia, já que traduz a evolução da ocupação de sua superfície e as atividades de preservação, além de contemplar elementos determinantes sobre a capacidade de infiltração e a retenção de água do escoamento superficial.

Neste sentido, a modelagem hidrológica é ferramenta cada vez mais utilizada e confiável para realização de estudos que objetivam avaliar as alterações do uso antrópico e suas implicações nas funções hidrológicas do solo. Seibt (2013) esclarece que os modelos hidrológicos permitem representar a fundamentação teórica, a disparidade espacial e a variabilidade temporal, considerando as características da bacia, como o solo, a vegetação, a topografia e os eventos chuvosos, pois possibilita ampla abordagem sobre os principais mecanismos e interações que se desenvolvem no ambiente urbano.

Evidencia-se a relevância por se buscar compreender o ciclo hidrológico na bacia, a distribuição espacial da chuva, as perdas por interceptação, por evapotranspiração, a infiltração da água no solo a água subterrânea, o escoamento superficial e 
sub-superficial, enfim, entender toda essa dinâmica por meio de modelos hidrológicos (Fritsch, 2013).

Neste sentido, objetivou-se avaliar medidas mitigadoras na atenuação dos efeitos decorrentes de chuvas intensas na bacia hidrográfica do córrego Botafogo em Goiânia utilizando modelagem hidrológica.

\section{Metodologia}

Primeiramente classificou-se a pesquisa, em seguida, apresentou-se a caracterização ambiental da sub-bacia do local estudado, bem como o clima da região. Após, os procedimentos técnicos operacionais que constam das seguintes etapas: preparação do banco de dados e mapeamentos temáticos, método racional e aplicação do modelo hidrológico. Por fim, a modelagem hidrológica face aos cenários propostos para atenuação dos efeitos do adensamento urbano, demonstrada pela apresentação de mapas/figuras.

\subsection{Caracterização da área de estudo}

\subsubsection{Características gerais da sub-bacia do córrego Botafogo}

A sub-bacia hidrográfica do córrego Botafogo (Figura1) drena área de $30,62 \mathrm{~km}^{2}$ e localiza-se na porção sul/central da capital Goiânia, Goiás (Goiânia, 2007).

Figura 1. Localização da sub-bacia hidrográfica do córrego Botafogo, Goiânia - Goiás.

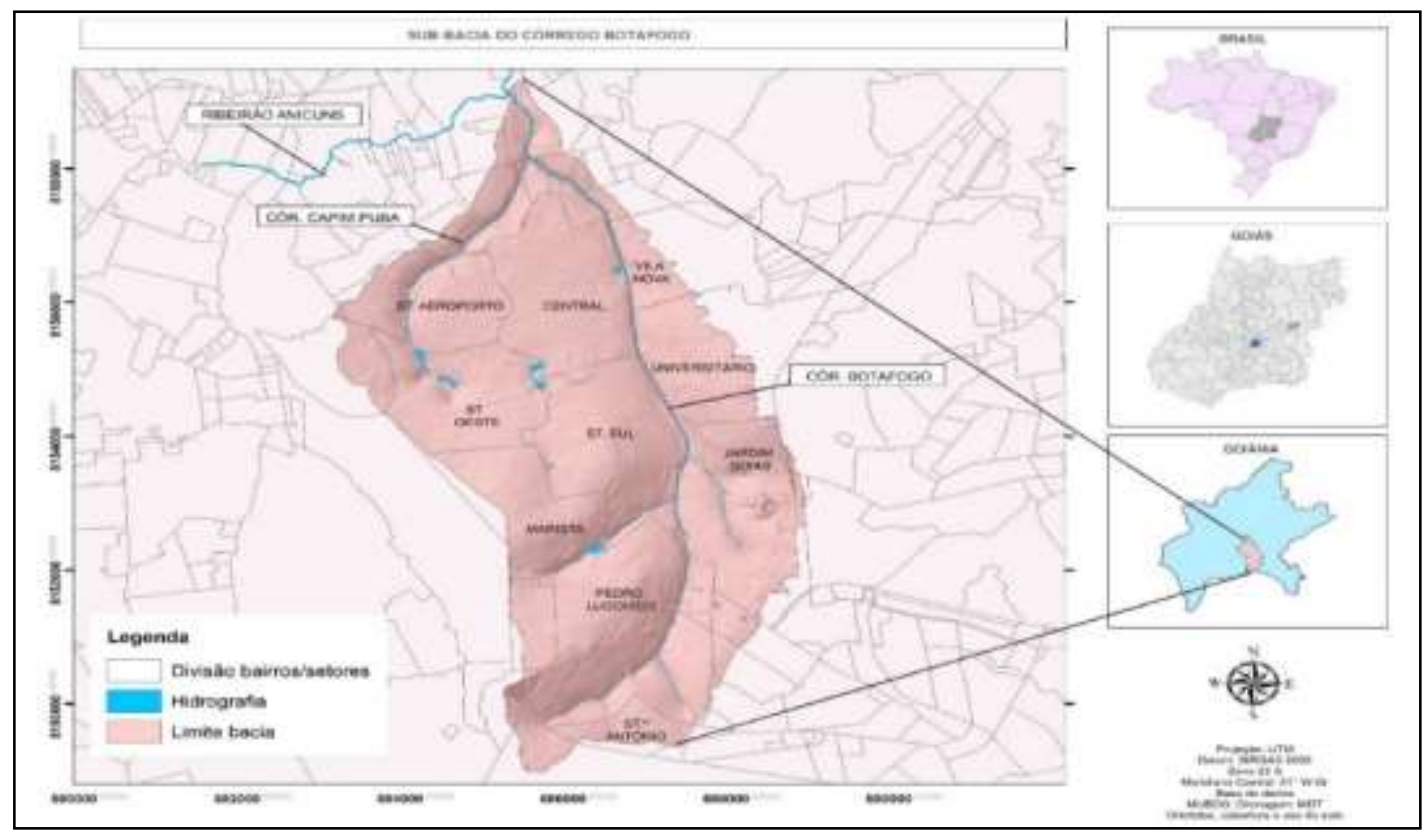

Fonte: Cartográfica - SECTEC (2018). Autores (2019).

O córrego Botafogo possui extensão de $9,8 \mathrm{~km}$ da nascente à foz, tendo seu percurso inserido em zona urbanizada de Goiânia (Seplam, 2018).

A dinâmica pluviométrica e climática na bacia, baseou-se nas características e descrições nos trabalhos de Romão (2006) e Nunes (2011), mostrando a tendência das chuvas distribuídas por meses ao longo do período de um ano, conforme o clima regional. 


\subsubsection{Clima: dinâmica atmosférica regional, intensidade, duração e frequência dos eventos pluviométricos}

A dinâmica pluviométrica e climática na bacia, baseou-se nas características e descrições apresentadas nos trabalhos de Romão (2006) e Nunes (2011), mostrando a tendência das chuvas distribuídas por meses ao longo do período de um ano, de acordo com o clima regional. Pelo fato de ocupar a porção central do continente, Goiás sofre influências da dinâmica atmosférica que afeta grande parte da América do Sul. Dessa forma, o padrão climático é caracterizado por um período quente e chuvoso e outro de estiagem com temperaturas mais amenas (Nunes, 2011).

O período chuvoso tende a ter início ao final do mês de setembro e início de outubro, com chuvas ainda em dias isolados em torno de $15 \mathrm{~mm}$ em série de até 3 dias. Nos meses de outubro e novembro, os eventos pluviométricos, ainda que ocorram em maior frequência, tendem a apresentar valores médios - em torno de $20 \mathrm{~mm}$ - e aqueles com menor frequência ficam em torno de $35 \mathrm{~mm}$, sendo que excepcionalmente podendo chegar a $60 \mathrm{~mm}$ (Nunes, 2011).

No que se refere ao período de maior intensidade pluviométrica, os meses mais chuvosos são de dezembro a março, com precipitação média mensal acima de $250 \mathrm{~mm}$ e média anual de cerca de $1500 \mathrm{~mm}$ (Romão, 2006). Ressaltando que no mês de janeiro, a frequência de precipitação tende a se reduzir, bem como a intensidade da mesma. Entretanto, existe a predisposição de ocorrência e eventos pluviométricos isolados, os quais podem atingir 70 ou até mesmo $100 \mathrm{~mm}$ (Nunes, 2011). Na Figura 2 percebe-se o comportamento anual das precipitações, conforme Silva (2021).

Figura 2. Precipitação mensal para o município de Goiânia, GO, no período de 1949 a 2019, em que no Boxplot a linha central representa a mediana, a parte inferior da caixa representa $25 \%$, a parte superior da caixa representa $75 \%$, e a linha contínua vertical representam os limites superior e inferior e * representa os outliers.

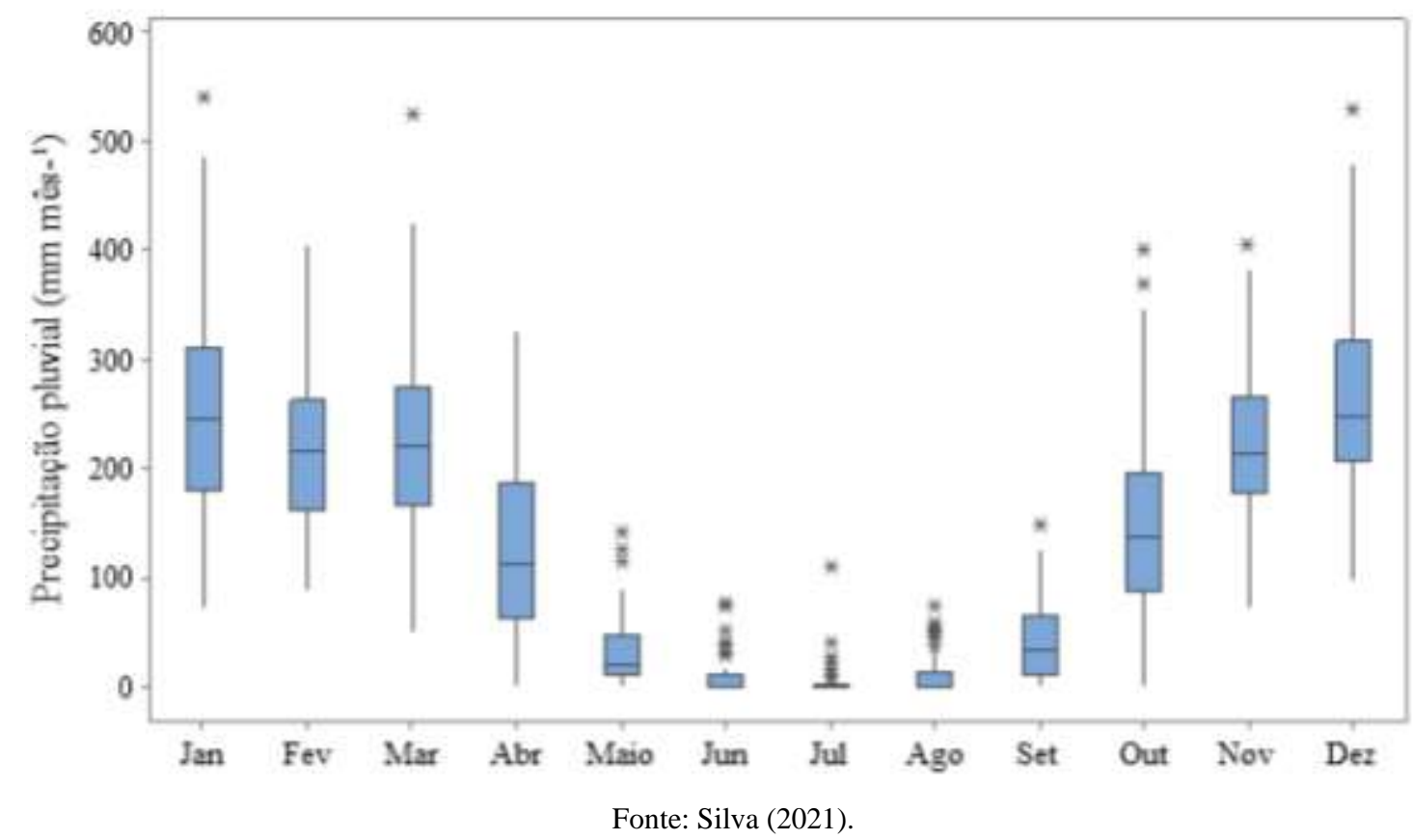

A redução das precipitações começa no mês de abril, o qual pode ser considerado como o último mês com chuva. Já a precipitação média dos meses menos chuvosos acontece de junho a agosto, ficando abaixo de 10 mm (Romão, 2006). As temperaturas mais elevadas durante o ano em Goiânia ocorrem nos meses de setembro, outubro, novembro e dezembro, com médias oscilando entre $29^{\circ} \mathrm{C}$ e $31^{\circ} \mathrm{C}$, muitas vezes chegando a índices superiores a $35^{\circ} \mathrm{C}$. Os meses mais frios correspondem aos meses junho e julho, com médias das mínimas oscilando entre $13^{\circ} \mathrm{C}$ e $18^{\circ} \mathrm{C}$. A esse mesmo período associam-se os menores índices de umidade relativa do ar, o qual apresenta variação térmica diária de até $10^{\circ} \mathrm{C}$ (Romão, 2006). 


\subsection{Procedimentos Técnico-Operacionais}

\subsubsection{Preparação do banco de dados e mapeamentos}

Todos os dados estão georreferenciados com base na projeção UTM, Datum SIRGAS 2000 e no fuso 22 S. Para aplicação do modelo hidrológico empregou-se imagens do satélite Landsat 5, 7 bandas ano 1988, 1998 e 2008, e imagem Landsat 8,13 bandas, ano 2018, com resolução espacial de 30 m e resolução espectral de sete bandas, obtidas do United States Geological Survey (USGS, 1988, 1998, 2008 e 2018).

Para recortes espaciais detalhados, localização e dimensionamento, foram usadas ortofotos de Goiânia, com 0,50 m de resolução, anos 1992, 2001, 2006, 2011 e 2016, da Secretaria Municipal de Desenvolvimento Urbano Sustentável (SEMDUS) e de arquivos vetoriais do Mapa Urbano Básico Digital de Goiânia (MUBDG), versão 25, da Secretaria Municipal de Ciência, Tecnologia e Inovação (SECTEC).

$\mathrm{Na}$ elaboração das variáveis morfométricas e morfográficas fez-se uso do Modelo Digital de Terreno em estrutura matricial, por meio de estereoscopia a partir das ortofotos do município de Goiânia, baseado em metodologia estabelecida por Nunes (2011), adotando-se equidistância das curvas de nível, de um metro de intervalo de altitudes.

\subsubsection{Método Racional}

Para determinar a modelagem hidrológica, procurou-se entender as variáveis que compõem o sistema hidrográfico na bacia, considerando o Método Racional. Para tanto, utilizou-se as imagens Landsat 8 para o ano de 2018, especificamente na respectiva data: 03/08/2018.

As estimativas de volume de escoamento se baseiam na avaliação dos tipos de solo, como na formação de grupos hidrológicos, nas condições de cobertura e uso, bem como na capacidade de retenção de água nos solos. Para a determinação das estimativas de escoamento superficial aplica-se o modelo hidrológico Método Racional. Os princípios foram adaptados por Mulvaney (1851) e Kuichling (1889), sendo uma das versões mais conhecidas expressa pela seguinte equação 1:

$$
Q_{\max }=\frac{C i A}{3,6} \quad \text { (Equação 1). }
$$

Em que:

Qmax é a vazão máxima estimada do escoamento superficial, em m³/s;

C é o coeficiente de escoamento superficial ou razão entre o volume escoado e o total precipitado, adimensional;

i é a média das intensidades máximas de precipitação, em $\mathrm{mm} / \mathrm{h}$, sendo que para a estimativa de vazão máxima a duração do evento pluviométrico deve ser igual ou maior que o tempo necessário para escoamento em toda a bacia;

A é a área da bacia, em km²; 3,6 é o fator de conversão entre unidades.

área da bacia, em km²; 3,6 é o fator de conversão entre unidades.

Os coeficientes de escoamento superficial foram determinados com base na proposta do Serviço de Conservação do Solo (SCS - Soil Conservation Service), aplicada pela Administração Federal de Autoestradas (FHA - Federal Highway Administration, 2013) do Departamento de Transportes dos EUA, baseando-se na precipitação efetiva, a qual resulta da relação entre a precipitação considerada e a capacidade de infiltração de água no solo. Essa relação considera também perda inicial de cerca de $20 \%$ do volume precipitado em decorrência das interceptações e retenções em depressões. Este coeficiente de armazenamento (S), resulta da avaliação de grupos hidrológicos, os quais levam em conta as características dos solos, especialmente textura e profundidade, características do terreno, bem como o tipo de cobertura e uso do solo, resultando em valores de CN (número de escoamento), conforme o Natural Resources Conservation Service (NRCS) - USDA (1997), de 
acordo com a equação 2. Para o cálculo, considerou-se o solo em condições normais, em que a precipitação acumulada nos últimos 5 dias é maior que $13 \mathrm{~mm}$ e menor que $53 \mathrm{~mm}$.

$$
\left.\mathrm{S}=\frac{25400}{\mathrm{CN}}-254 \quad \text { (Equação } 2\right) .
$$

Já os coeficientes de escoamento resultam da razão entre a precipitação efetiva ou volume convertido em escoamento superficial e a precipitação total a ser considerada, como apresentado na Equação 3:

$$
C=\left[\frac{[p-0,2 s)^{2}}{(p+0,8 s)^{2}}\right] * 1 / P \quad \text { (Equação 3). }
$$

em que:

$\mathrm{C}=$ coeficiente de escoamento superficial ou razão entre o volume escoado e o total precipitado, adimensional.

Para aplicação das Equações 2 e 3, baseia-se nos números de escoamento superficial (CN) para cada o tipo de condição do terreno na bacia, conforme apresentado no Tabela 1.

Tabela 1. Classes de uso e ocupação do solo e respectivos números de escoamento superficial (CN).

\begin{tabular}{ll}
\hline Condição do Terreno & CN \\
\hline Área Edificada & 98 \\
Superfície Pavimentada & 97 \\
Solo Exposto Compactado & 76 \\
Solo Exposto não Compactado & 68 \\
Gramínea Compactada & 66 \\
Gramínea não compactada & 61 \\
Árvores Isoladas & 62 \\
Mata de Galeria/Vegetação Densa & 29 \\
\hline
\end{tabular}

Fonte: Tucci e Marques (2001)

Já os coeficientes de escoamento resultam da razão entre a precipitação efetiva ou volume convertido em escoamento superficial e a precipitação total a ser considerada, como apresentado na equação 4:

$$
C=\left[\frac{(p-0,2 s)^{2}}{(p+0,8 s)}\right] * 1 / P \quad \text { (Equação 4). }
$$

Em que:

C é o coeficiente de escoamento superficial ou razão entre o volume escoado e o total precipitado, adimensional.

As médias das intensidades máximas de precipitação foram estimadas de acordo com a relação proposta por Villela \& Mattos (1975), que relaciona a intensidade-duração-frequência, entendido pela sigla IDF, dos eventos meteorológicos, utilizando o histórico de chuvas disponibilizados pelo INMET, para o período correspondente a esta pesquisa, conforme sistematizado por Oliveira et al. (2005) para a região de Goiânia por meio da seguinte equação 5:

$$
I m=\frac{\mathrm{KxTr}^{\mathrm{a}}}{(\mathrm{t}+\mathrm{b})^{\mathrm{c}}} \Rightarrow \operatorname{Im}=\frac{920,45 \times \operatorname{Tr}^{0,1432}}{(\mathrm{t}+12)^{0,7599}} \quad \text { (Equação 5). }
$$

Em que: 
Im é a média das intensidades máximas de precipitação, em $\mathrm{mm} / \mathrm{h}$;

$\mathrm{K}$, a, b e c são os parâmetros próprios da estação climatológica;

T é o tempo de retorno, em anos para um evento extremo;

t é o tempo de concentração do escoamento superficial, que deve ser menor ou igual ao tempo de duração da precipitação na área da bacia, em minutos.

Considerou-se um tempo de retorno de 50 anos, compatível com áreas comerciais e vias arteriais de tráfego (Porto et al., 2004). Já os tempos de duração das precipitações resultaram do tempo de concentração do escoamento superficial, de toda a bacia, estimados no período de estudo, de 1988 até 2018. Estes são determinados pelo Método Cinemático, conforme o SCS (1971) por meio da equação 6:

$$
T c=1 / 60 \times \Sigma \frac{L i}{V i} \quad \text { (Equação 6). }
$$

Em que:

Tc é o tempo de concentração do escoamento superficial, em min;

1/60 é o fator de transformação de segundos para minutos;

Li é o comprimento de fluxo no segmento considerado, em m;

Vi é a velocidade do escoamento superficial, em $\mathrm{m} / \mathrm{s}$.

A velocidade de escoamento superficial foi estimada com base na avaliação dos coeficientes de escoamento e da declividade, por meio da seguinte equação (Porto, 1995), conforme equação 7:

$$
\mathrm{Vi}=\mathrm{C} \times \mathrm{Si}^{0,5} \quad \text { (Equação 7). }
$$

Em que:

Vi é a velocidade de escoamento superficial, em $\mathrm{m} / \mathrm{s}$;

C é o coeficiente de escoamento superficial, adimensional;

Si é a declividade, em \%, elevada ao expoente 0,5 , em $\mathrm{m} / \mathrm{m}$;

Aplicou-se um coeficiente de retardamento em função da área da mesma, resultando no que se conhece como Método Racional Modificado, conforme proposto por Pinto et al. (1976) e Euclydes (1987), cuja fórmula é apresentada pela equação 8:

$$
\theta=0,278-0,00034 \mathrm{~S} \quad \text { (Equação 8). }
$$

Em que:

$\theta$ é o coeficiente de retardamento em função da área da bacia;

0,278 e 0,00034 são constantes;

Ressalta-se que a variável área da bacia é utilizada de forma cumulativa, isto é, transferência do volume de células a montante para aquela a jusante, que resultará no acúmulo de escoamento superficial em função da área de contribuição específica (Nunes \& Borba, 2018). 


\subsubsection{Aplicação esquematizada do modelo hidrológico}

De forma a esquematizar a sequência metodológica utilizada na aplicação do modelo hidrológico, é apresentada no fluxograma básico, por meio da Figura 3. Ressalta-se que os cálculos foram realizados por meio de modelagem no software ArcGis 10.3, a partir álgebra matricial.

Figura 3. Fluxograma metodológico para aplicação do modelo hidrológico.

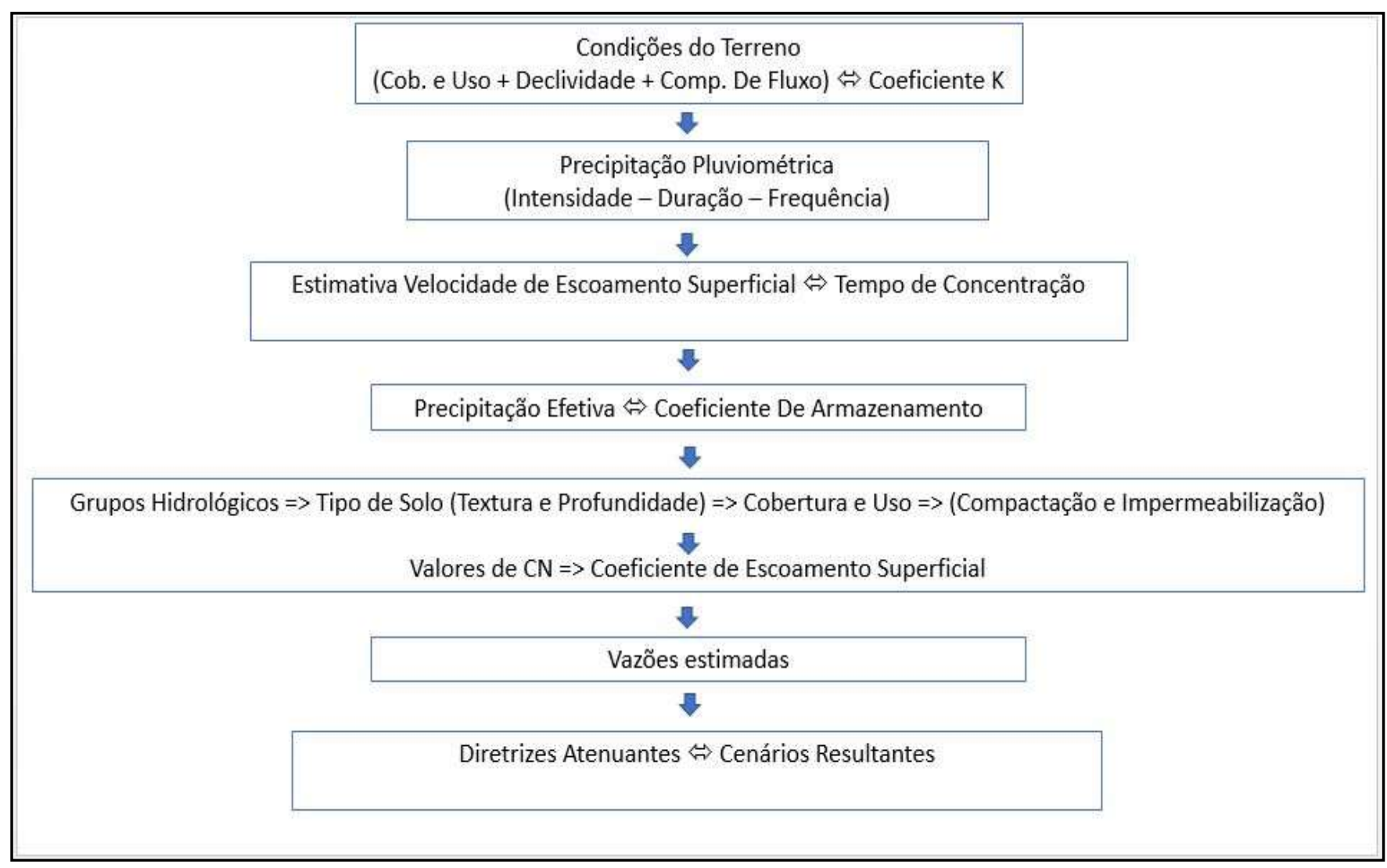

Fonte: Autores (2019).

Primeiramente, analisou-se o input de energia no sistema hidrológico na sub-bacia, sendo este ocasionado pela precipitação pluviométrica, por meio da equação 5 , estabelecendo a relação entre intensidade, duração e frequência de chuva. Em seguida, verificou-se a estimativa de velocidade de escoamento pela equação 7 e tempo de concentração pela equação 6, fazendo-se a correção necessária para o tempo de retardamento, por meio da equação 8 .

Paralelamente, estabeleceu-se a relação entre os grupo hidrológicos - tipo de solo (textura e profundidade) e cobertura e uso - e como estes influenciam diretamente na convergência ou divergência de fluxo na sub-bacia do córrego Botafogo, principalmente potencializados pelas as modificações antrópicas (compactação e impermeabilização do solo), para enfim utilizar-se da equação 2 para determinar valores de precipitação efetiva e da equação 3 para estabelecer o coeficiente de armazenamento, determinando o $\mathrm{CN}$ (número de escoamento). Posteriormente aplicou-se a equação 4 para determinar o coeficiente de escoamento superficial e finalmente a equação 1 para os valores de vazões máximas.

Assim, determinado a estimativa do escoamento superficial na sub-bacia, realizou-se a aplicação dos dois cenários propostos como medidas para atenuação do adensamento urbano na sub-bacia estudada. 


\subsection{Modelagem hidrológica face aos cenários propostos para atenuação dos efeitos do adensamento urbano}

Realizou-se a identificação das principais linhas de fluxo e o potencial de contribuição dos mesmos, de forma a confrontar com diretrizes propostas para atenuar os efeitos do adensamento urbano na bacia do córrego Botafogo. Assim, destaca-se as seguintes diretrizes avaliadas:

Cenário 1: Implementação do Plano para Controle de Águas Pluviais e de Drenagem Urbana (Lei Municipal de Goiânia $n^{\circ}$ 9511/2014) que estabelece área mínima permeável dentro de cada lote: realizou-se teste considerando $15 \%$ do terreno de cada lote sendo destinada à infiltração de água na bacia e avaliou-se o impacto que tal aplicação poderia proporcionar;

Cenário 2: Construção de bacias de retenção/contenção de fluxo hídrico superficial: avalia-se as condições do terreno, mediante a definição das principais linhas de fluxo, que consequentemente mais contribuem para o efeito acumulativo no canal principal da sub-bacia durante as chuvas, e determinar os locais mais apropriados à construção de estruturas destinadas à captação de água e aumento do tempo de concentração do escoamento superficial ao longo dos fluxos hídricos.

Para aplicação dos cenários estabelecidos, além da utilização da modelagem hidrológica embasada pelo método racional, conforme já apresentado, foi necessário estimar a vazão suportada pelo canal do córrego Botafogo. Primeiramente é necessário determinar a velocidade do canal. Portanto, utilizou-se da Fórmula de Manning, a mais popular para dimensionamento de condutos livres que considera rugosidade do canal (Tomaz, 2010). Segue a equação 9:

$$
\mathrm{V}=(1 / \mathrm{n}) * \mathrm{R}^{2 / 3} * \mathrm{~S}^{1 / 2} \quad \text { (Equação 9). }
$$

Sendo:

V é a velocidade média na seção $(\mathrm{m} / \mathrm{s}) ; \mathrm{n}=$ coeficiente de Manning tem as dimensões TL $-1 / 3$;

$\mathrm{R}$ é o raio hidráulico (m). O raio hidráulico é o quociente entre a área molhada e o perímetro molhado;

$\mathrm{S}$ é a declividade $(\mathrm{m} / \mathrm{m})$. A inicial "S" vem da palavra inglesa Slope que quer dizer declividade.

A seção transversal escolhida no canal para fornecimento das variáveis que considerou área próximo ao exutório, no final da seção canalizada do córrego Botafogo, local onde o canal é turbulento devido toda contribuição da sub-bacia à montante. Para determinar o valor de R (raio hidráulico) foi baseada no trabalho de Ferreira, Pimenta \& Viana (2014), o n (coeficiente de rugosidade de Manning) para canais abertos em concreto foi baseado na tabela determinada pelo trabalho de Porto (1998) apud Tomaz (2010) e a declividade (S) foi obtida pela topografia do terreno determinada na modelagem aplicada.

Aplicado a fórmula, obteve-se velocidade média na seção (V) de 0,59667 m.s.-1. Com área da seção transversal (A) de 44,44 m², baseada nas dimensões do trabalho de Ferreira, Pimenta \& Viana (2014), foi possível estimar a vazão suportada pelo canal do córrego Botafogo, que é vazão $(\mathrm{Q})=26,51 \mathrm{~m}^{3} \cdot \mathrm{s}^{-1}$. 


\section{Resultados e discussão}

\subsection{Cenário 1: lotes na sub-bacia com $15 \%$ de área permeável}

Considerou-se as condições de cobertura e uso do solo no ano de 2018 para gerar o cenário 1 . Em relação a cobertura e uso do solo, a classificação de área foi: área edificada $(68,61 \%)$, pavimentada $(23,18 \%)$, solo exposto $(0,21 \%)$, gramínea compactada $(0,32 \%)$, árvore isolada $(2,59 \%)$ e vegetação densa $(1,22 \%)$. As porcentagens são referentes ao adensamento urbano da área de estudo, incluindo a divisão dos lotes na área edificada.

Na Figura 4 apresenta-se a evolução temporal ocorrida na sub-bacia, para interpretação quantitativa e análise.

Figura 4. Evolução temporal da cobertura e uso do solo para os anos de 1988, 1998, 2008 e 2018 na sub-bacia do córrego Botafogo, Goiânia, GO.

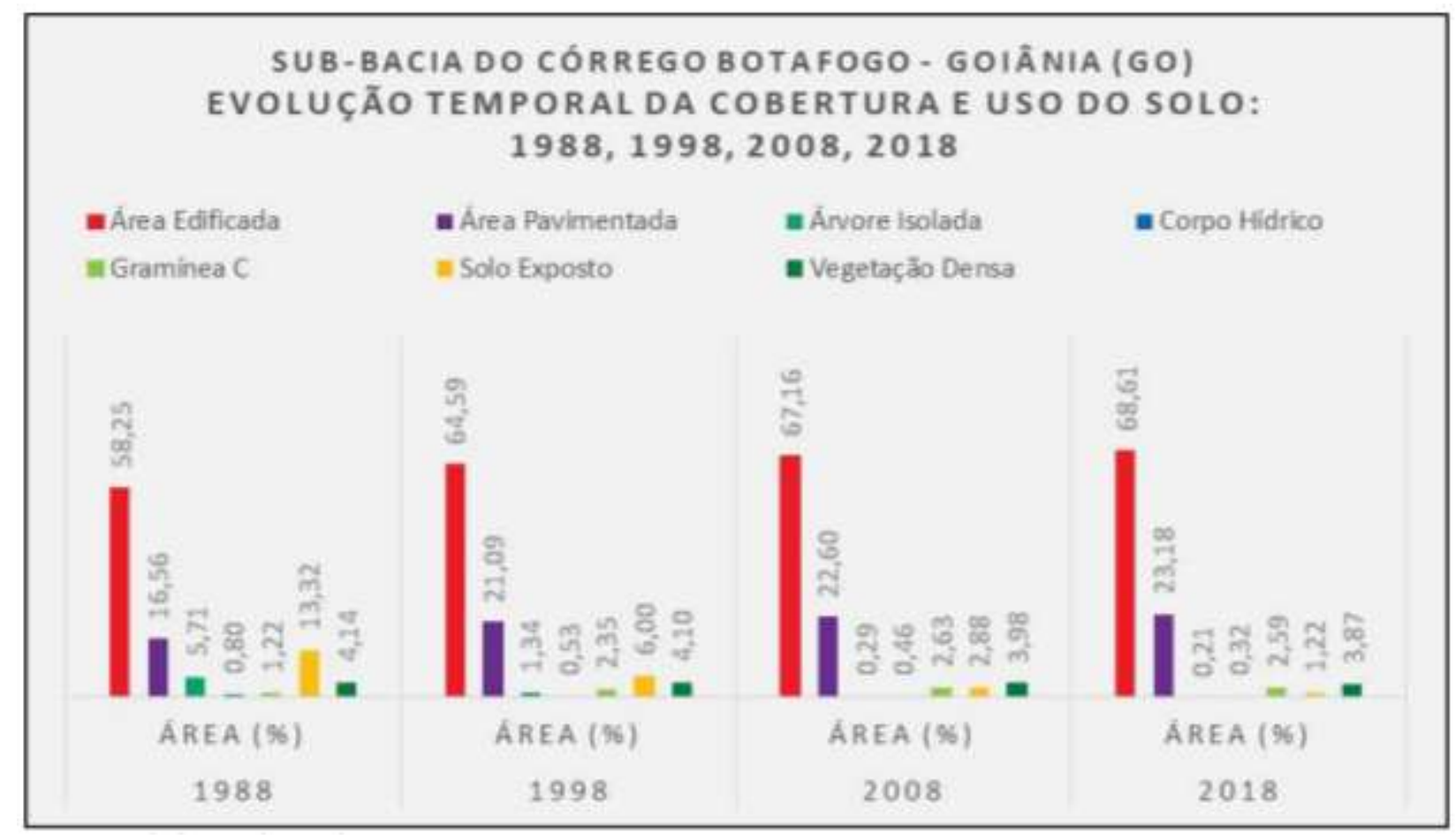

Fonte: Autores (2019).

A partir das variáveis determinadas, que influenciam na dinâmica hidrológica da bacia, foi possível determinar a estimativa de vazão, considerando este cenário de $15 \%$ de área permeável por lote, seguindo o Plano para Controle de Águas Pluviais e de Drenagem Urbana (Lei Municipal de Goiânia no 9511/2014) que estabelece área mínima permeável dentro de cada lote: realizou-se teste considerando $15 \%$ do terreno de cada lote sendo destinada à infiltração de água na bacia e como este cenário pode influenciar com as principais linhas de fluxo que contribuem para o canal principal (Figura 5).

Percebe-se que as linhas de fluxo que convergem para o canal do córrego Botafogo, visto que o cenário considerou a cobertura e uso do solo real, havendo apenas a modelagem que subtrai $15 \%$ de área permeável por lote, para verificar a provável redução na vazão que esta medida pode ocasionar. 
Figura 5. Estimativa de vazão para cenário com 15\% de área permeável por lote na sub-bacia do córrego Botafogo, Goiânia, GO.

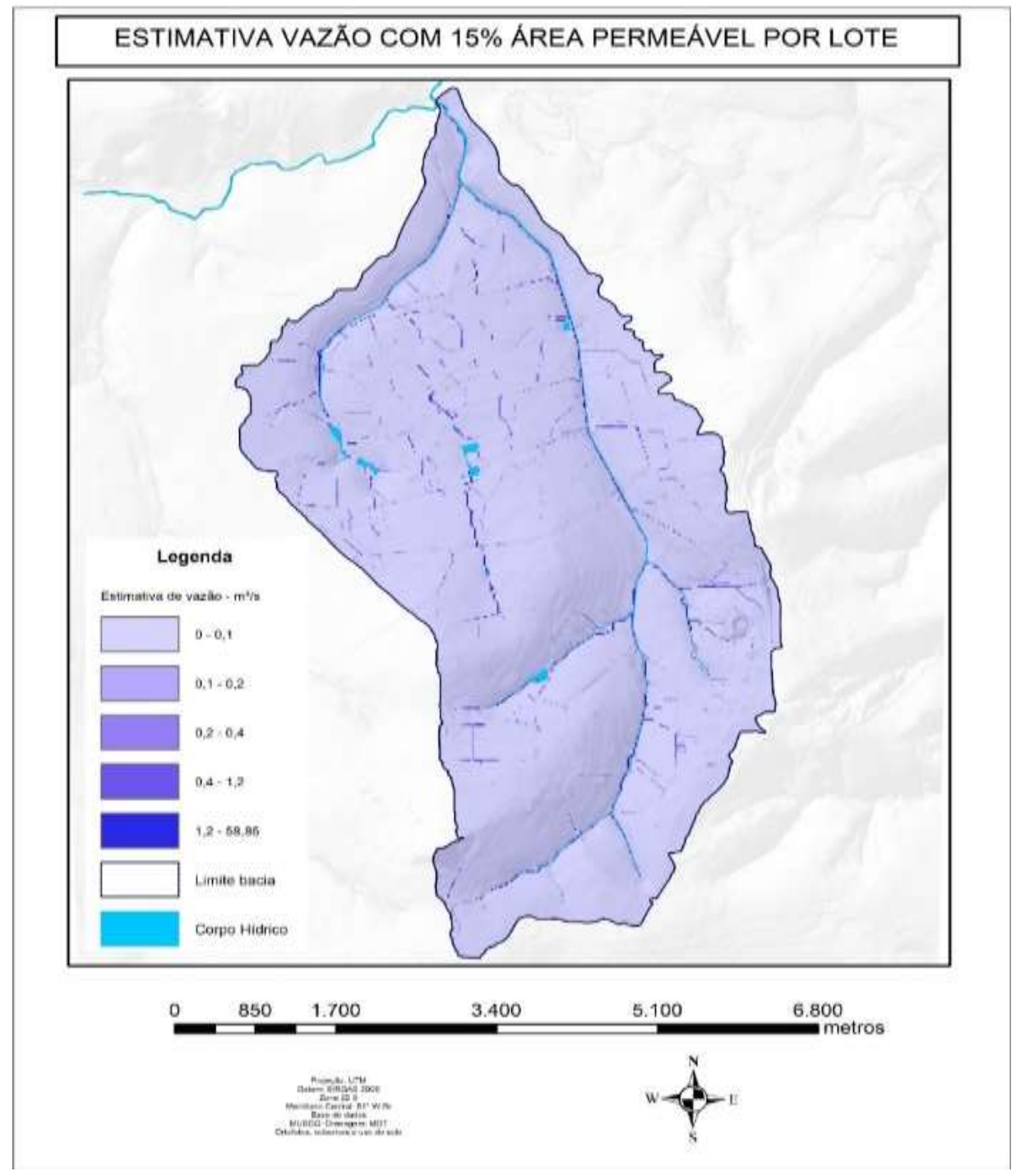

Fonte Cartográfica: SECTEC (2018). Elaboração cartográfica pelos autores (2019).

Constata-se que este cenário não reduziria a vazão, sendo que o real é $62,27 \mathrm{~m}^{3} \cdot \mathrm{s}^{-1}$ para 2018 . Com o cenário de $15 \%$ (Figura 5) de área permeável por lote, para mesma cobertura e uso, considerando ano de 2018, a redução é praticamente insignificante, visto que a estimativa de vazão ficaria em $58,85 \mathrm{~m}^{3} \cdot \mathrm{s}^{-1}$. São vazões muito acima da suportada pelo canal do córrego Botafogo, que é de $26,51 \mathrm{~m}^{3} / \mathrm{s}$, conforme determinada pelos cálculos realizados considerando a fórmula de Manning (Equação 9). Portanto, de acordo com Araújo, Almeida \& Guerra (2008), quando acontece o processo de urbanização, os espaços permeáveis, inclusive as áreas com presença de vegetação, são submetidas a diferentes tipos de usos, os quais tendem a impermeabilizar a superfície, causando aumento no escoamento superficial e deixando os cursos hídricos suscetíveis à alagamentos e inundações.

Analisando a Figura 6 é possível verificar a estrutura (divisão) da sub-bacia com a inserção dos lotes na área edificada na imagem mais à esquerda. Sendo que CN para área edificada é de 98, neste caso subtraindo $15 \%$ de área permeável por lote, em toda a bacia, o novo $\mathrm{CN}$ calculado é 83.3 no lote de área impermeável. A partir do valor de CN calculado, aplicou-se as equações do método racional. 
Figura 6. Cobertura e uso, coeficiente de infiltração, precipitação efetiva e coeficiente de escoamento superficial para cenário com $15 \%$ de área permeável por lote na sub-bacia do córrego Botafogo, Goiânia, GO.

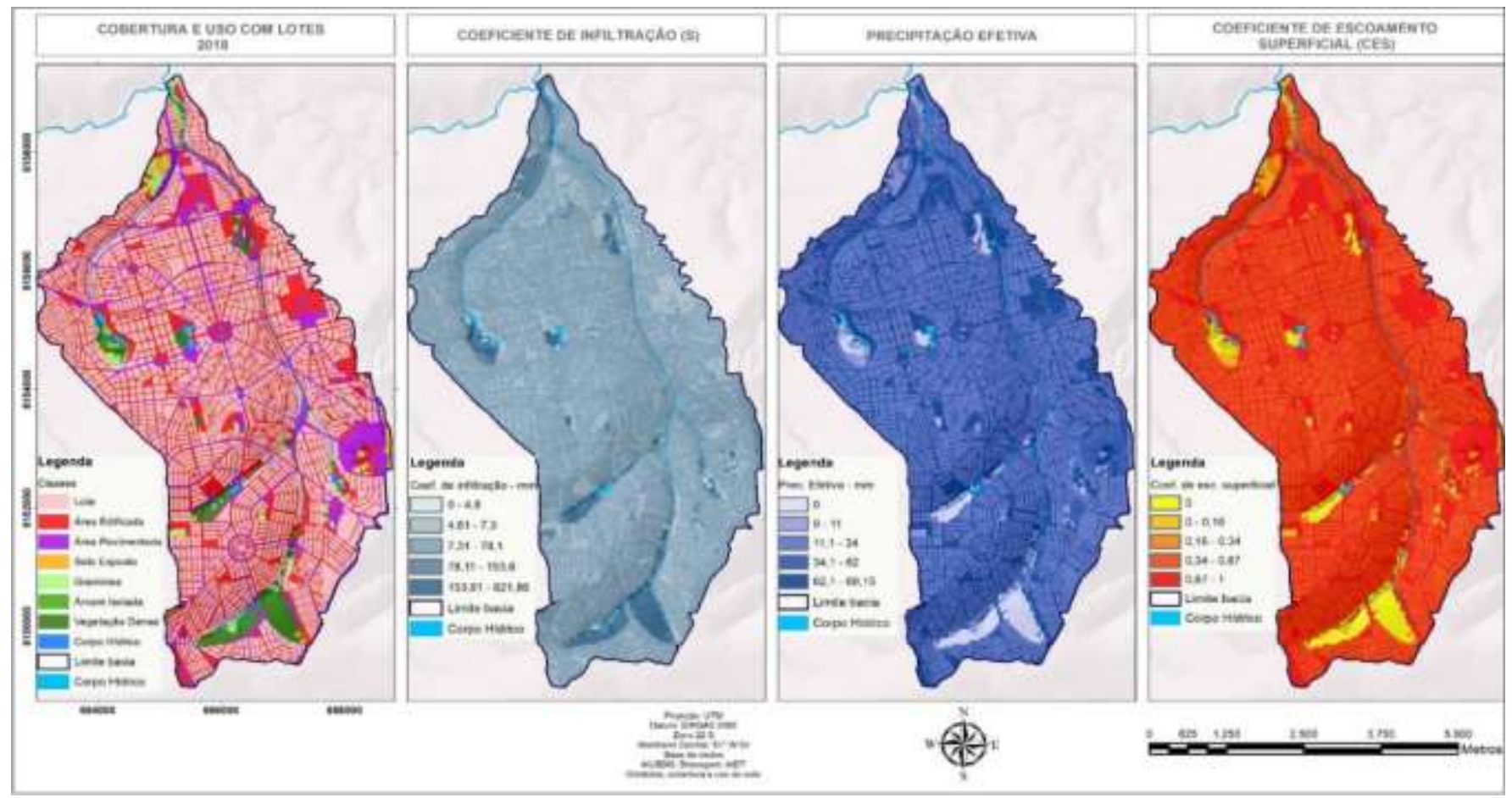

Fonte: Cartográfica - SECTEC (2018). Elaboração cartográfica pelos autores (2019).

Em relação às alterações no sistema hidrológico, o modelo adotado subtraiu $15 \%$ de área permeável em cada lote. Quanto ao coeficiente de infiltração, verifica-se que as áreas verdes continuam proporcionando maior taxa de infiltração, e que diferente dos valores definidos de forma geral com a inserção dos lotes, o coeficiente de infiltração com menor contribuição (0-4,8 mm) fica exclusivamente onde área com terreno é totalmente edificada e/ou pavimentada (impermeabilizada), com os lotes passando a contribuir na infiltração (4,81-7,3 mm). Nunes (2007) apud Fritsch (2013), afirma que o fenômeno do sistema hidrográfico, tais como, as precipitações, evapotranspiração, infiltração, escoamentos superficiais, escoamentos subterrâneos e deflúvios são relacionados para estabelecer a capacidade de armazenamento de água de uma bacia.

Aplicando as fórmulas, obtém-se a precipitação efetiva que também segue basicamente o que ocorreu com o coeficiente de infiltração, visivelmente há melhor distribuição com os lotes, permanecendo 0 mm nas áreas verdes, pois onde ocorre maior contribuição com a infiltração. Por sua vez, as áreas edificadas e pavimentadas, onde os valores de precipitação efetiva (coluna d’água) permanecem maiores (62,1-69,15 mm), sendo que com os lotes com porcentagem para permeabilização, há parte da área que fica com precipitação efetiva intermediária (11,1-34,00 mm).

O coeficiente de escoamento superficial é inversamente proporcional ao coeficiente de infiltração, então, permanecendo nesta lógica, percebe-se que não ocorre escoamento nas áreas verdes, onde infiltração é elevada, e maior contribuição ao escoamento superficial acontece nas áreas impermeáveis (edificadas e pavimentadas), sendo que com a subtração com $15 \%$ de cada lote com faixa permeável, esta classe fica com escoamento intermediário (0,34-0,87). Gorniack (2014) afirma que à medida que a infiltração diminui diante do avanço da impermeabilização, o escoamento superficial aumenta devido esse escoamento e infiltração serem inversamente proporcionais.

Considerando intensidade média máxima de precipitação de 69,15 mm/h (2018), apresentando a vazão real de contribuição da sub-bacia de $62,27 \mathrm{~m}^{3} \cdot \mathrm{s}^{-1}$, para 2018 , quanto a vazão de $58,85 \mathrm{~m}^{3} \cdot \mathrm{s}^{-1}$ no cenário com $15 \%$ de área permeável por lote, são vazões muito acima da suportada pelo canal do córrego Botafogo, que é de $26,51 \mathrm{~m}^{3} . \mathrm{s}^{-1}$, conforme determinada 
pelos cálculos realizados considerando a fórmula de Manning.

Ressalta-se que como a sub-bacia já se encontrava urbanizada quando foi estabelecido o Plano para Controle de Águas Pluviais e de Drenagem Urbana (Goiânia, 2014), portanto, não houve medidas para readequação dos lotes de modo a garantir esta área mínima permeável. De qualquer forma, com a simulação deste cenário apresentado, evidencia-se que 15\% de área permeável por lote é insuficiente para reduzir substancialmente a vazão que causa efeito acumulativo no canal do córrego Botafogo, visto que a vazão suportada pelo canal é de $26,51 \mathrm{~m}^{3} \cdot \mathrm{s}^{-1}$.

\subsection{Cenário 2: Sugestão de locais para construção de bacias e barragens de contenção nas principais linhas de fluxo.}

O Cenário 2 trata-se de sugestões para a construção de bacias ou barragens de retenção/contenção de fluxo hídrico superficial ou subsuperficial. Para tanto, avalia-se as condições do terreno, considerando a cobertura e uso do ano de 2018, mediante a definição das principais linhas de fluxo que mais contribuem para o efeito acumulativo no canal do córrego Botafogo, assim determinar os locais mais apropriados à construção de estruturas destinadas à captação de água e aumento do tempo de concentração do escoamento superficial ao longo do fluxo hídrico.

As bacias de retenção são estruturas que devem ser construídas que servem como se fossem lagos ao longo dos canais, para casos em que não há superfícies (terrenos) disponíveis. Estas estruturas devem ser viabilizadas nos locais onde se encontram as principais linhas de fluxo, que possam diminuir a vazão de contribuição ao canal em picos de chuva, que causam alagamentos e/ou transbordamentos. Ressalta-se que não foi considerado aspectos legais sobre a propriedade dos terrenos para receber estas estruturas de drenagem urbana, podendo ser necessária desapropriação, se for o caso.

Com a aplicação do modelo, identificou-se algumas linhas de fluxo que contribuem para o efeito acumulativo no canal, a partir dos divisores de água. Coelho Neto (2001), apud Silva et al. (2004) afirma que as bacias de drenagem podem ser desmembradas em um menor número de sub-bacias, dependendo do ponto de vista de saída considerando ao longo de seu eixo-tronco ou canal coletor.

Identificou-se na Figura 7 as principais linhas de fluxo que convergem ao longo do córrego Botafogo, considerando o ano de 2018. As principais linhas são provenientes em maior proporção pela margem direita, sendo pontos de contribuição: área pavimentada dos estacionamentos shopping Flamboyant + hipermercados, estacionamento Estádio Serra Dourada, Avenida Universitária + Praça Universitária e Avenida Anhanguera. À margem esquerda, as principais linhas de fluxo que são advindas da impermeabilização ao longo do córrego Areião (Setor Marista + Setor Sul), Avenida 10 (Praça Cívica - Centro), Avenida Anhanguera e Avenida Independência. 
Figura 7. Estimativa de vazão e principais linhas de fluxo que convergem para o córrego Botafogo e locais indicados à construção de bacias ou barragens de contenção na sub-bacia estudada. (Ano: 2018).

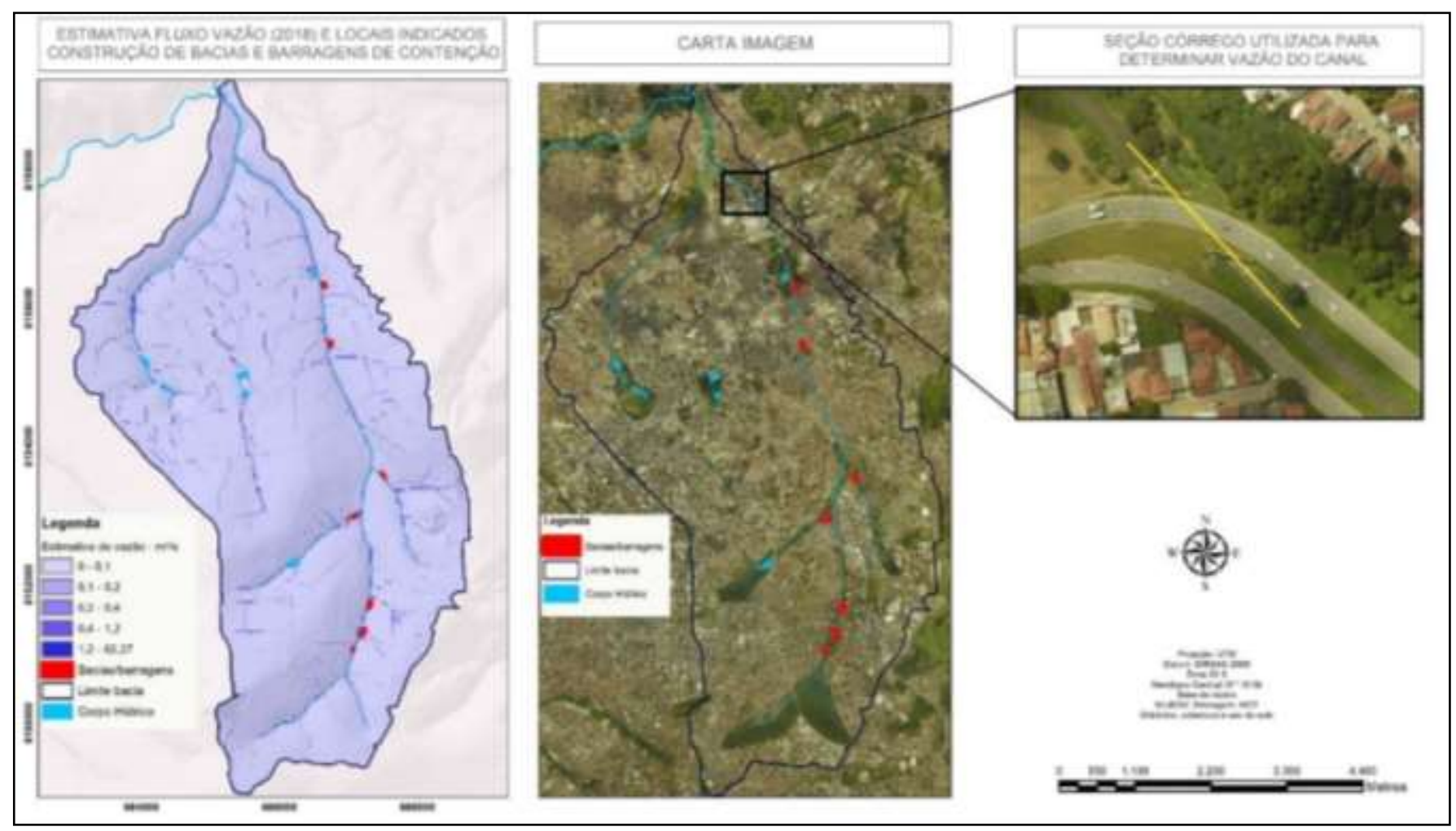

Fonte: Cartográfica - Semdus/MUBDG/SECTEC (1992, 2001, 2006, 2011 e 2016). Elaboração cartográfica pelos autores

Assim, os locais indicados para construção de bacias de contenção são localizados entre a Marginal Botafogo e a Avenida Anhanguera, próximo à Avenida Universitária e Marginal Botafogo e em dois locais rentes ao canal principal à margem direita onde recebem contribuições do shopping Flamboyant + hipermercados. As barragens são indicadas no próprio canal do córrego Botafogo, próximos a nascente, onde a declividade contribui com maior velocidade do escoamento superficial, à margem esquerda no córrego Areião e na margem direita no córrego Sumidouro.

Ressalta-se que tais estruturas devem funcionar conforme dispositivos seguros, sendo que no início da chuva o fluxo não deva ser interceptado, tendo em vista que no início de precipitação nem todo o fluxo converge para o canal principal, portanto é necessário deixar o fluxo fluir. Isto se dá pelo fato de que estas estruturas deverão ser acionadas para diminuir a vazão de contribuição antes de chegar ao córrego Botafogo, ou seja, funcionarão efetivamente a partir dos 60 minutos (1 h) de chuva, considerando a Intensidade Média das Máximas de Precipitação (IMMP) e precipitação efetiva para ano de 2018, pois é nesse tempo de concentração que o canal atinge a vazão máxima suportada de $26,51 \mathrm{~m}^{3}$. $\mathrm{s}^{-1}$, conforme determinado pela utilizando-se a Fórmula de Manning.

Neste artigo, focou-se na indicação dos pontos de implantação destes barramentos de retenção de água da chuva, não sendo objeto o dimensionamento dos mesmos, que deverá ser realizado em função das disponibilidades das áreas físicas urbanas.

\section{Considerações Finais}

Toda a sub-bacia do córrego Botafogo sofreu alterações na dinâmica hidrológica, com pontuais locais de alagamentos e enxurradas, principalmente na porção oeste-central. Porém, o local mais alarmante é a faixa ao longo do canal principal, no 
qual se somam as características topográficas, falhas no sistema de drenagem associados ao tipo de cobertura e uso do solo altamente adensado.

Com a simulação do cenário $1,15 \%$ de área permeável por lote seria insuficiente para reduzir substancialmente a vazão que causa efeito acumulativo no canal do córrego Botafogo, e que esta medida se tornaria inviável, visto que a sub-bacia já se encontra adensada, demonstrando que o Plano para Controle de Águas Pluviais e de Drenagem Urbana não apresenta alternativas para casos como este, em que lotes já consolidados anteriormente ao plano foram totalmente impermeabilizados.

Com o cenário 2, quanto à prospecção de locais indicados a serem construídos bacias e/ou barragens de contenção, percebe-se que são estruturas viáveis de serem construídas e que poderão minimizar a vazão de contribuição que chega no córrego Botafogo.

Diante dos fatos e considerando as linhas de fluxos que contribuem com o efeito acumulativo no canal principal, fazse necessário a aplicação de medidas para prevenir os episódios de alagamentos e transbordamentos no córrego Botafogo, ficando o alerta aos órgãos gestores, que devem se atentar na reformulação das medidas estruturais e não-estruturais de drenagem urbana a serem aplicadas.

\section{Referências}

Araújo, G. H. S., Almeida, J. R., \& Guerra, A. J.T. (2008). Gestão Ambiental de Áreas Degradadas. Bertrand Brasil.

Carvalho, D. F. (2014). Planejamento e manejo da água na agricultura irrigada. Universidade Federal Rural do Rio de Janeiro - UFRRJ. Editora UFV.

Euclydes, H. P. (1987). Saneamento agrícola. Atenuação de cheias: metodologia e projeto. Rural Minas.

Ferreira, A. S., Pimenta, G. R., \& Viana, E. S. (2014). Estudo de Caso de uma Seção Canalizada da Bacia do Córrego Botafogo na Cidade de Goiânia-GO. Goiânia: Faculdades Objetivo.

FHA - Federal Highway Administration (2013). Urban Drainage Design anual, Hydraulic Engineering. (3a ed.), National Highway Institute

Fritsch, F. E. D. (2013). Influência do uso e ocupação do solo nas vazões de pico na bacia hidrográfica do alto Rio Ligeiro, Pato Branco - PR. Monografia de Graduação na Universidade Tecnológica Federal do Paraná. Pato Branco, Brasil.

Goiânia. (2007). Plano Diretor. Lei Complementar $n^{o} 171$ de 29 de maio de 2007. Secretaria Municipal de Planejamento e Urbanismo - SEPLAM. http://www.goiania.go.gov.br/download/legislacao/PLANO_DIRETOR_DO_MUNICIPIO_DE_GOIANIA_2007.pdf

Goiânia. (2014). Plano para controle de águas pluviais e de drenagem urbana. Lei Municipal no 9511/2014. Prefeitura Municipal. Diário Oficial do Município de Goiânia, 2014. https://www.goiania.go.gov.br/html/gabinetecivil/sileg/ dados/legis/2014/lo20141215000009 511.pdf

Gorniack, A. (2014). Avaliação de Método de Controle do Escoamento Superficial para Drenagem Urbana Sustentável na Bacia do Rio Itapocu - SC. Dissertação de Mestrado em Planejamento Territorial e Desenvolvimento Socioambiental, Universidade Estadual de Santa Catarina, Florianópolis, Brasil.

Kuichling, E. (1889). The relation between the rainfall and the discharge of sewers in populous districts. Transactions of the American Society of Civil Engineers, 20 (1)1-60. https://doi.org/10.1061/TACEAT.0000694.

Marques, P. H. G. (2009). Diagnóstico Ambiental da Microbacia Hidrográfica, do Córrego Samambaia, Município de Goiânia. Monografia de Graduação. Bacharelado em Geografia, Instituto de Estudos Socioambientais - IESA, Universidade Federal de Goiás, Goiânia, Brasil.

Mulvaney, T. J. (1851). On the use of self-registering rain and flood gauges in making observations of the relations of rainfall and flood discharges in a given catchment. Transactions of the. Institution of Civil Engineers of Ireland, 4(2), 18-33.

Nunes, E. D. \& Borba, L. L. (2018). Avaliação dos efeitos do adensamento urbano na dinâmica hidrológica de bacias hidrográficas - Aparecida de Goiânia GO. Boletim Goiano de Geografia. Goiânia, 38(2) 205-226. 10.5216/bgg.v38i2.54617.

Nunes, E. D. (2011). Ensaio Sobre Modelagem de Bacia Hidrográfica no Contexto dos Sistemas Dinâmicos - Ribeirão Lajeado - Goiânia - GO. Dissertação (Mestrado) - Universidade Federal de Goiás, Instituto de Estudos Socioambientais.

Oliveira, L. F. C., Cortês, F. C., Wehr, T. R., Borges, L. B., Sarmento, P. H. L., \& Griebeler, N. P. (2005). Intensidade-duração-frequência de chuvas intensas para localidades no estado de Goiás e Distrito Federal. Pesquisa Agropecuária Tropical, Goiânia, 35(1), 13-18.

Pinto, N. L. S, Holtz, A. C. T., Martins, J. A., \& Gomide, F. L. S. (1976). Hidrologia básica. Editora Edgard Blücher.

Porto, R. L. L. (1995). Escoamento superficial direto. In: Tucci, C. E. M., Porto, R. L. L., \& Barros, M. T. de. (Org.). Drenagem urbana. (pp 107-162). Porto Alegre: ABRH

Porto, R. L. L., Zahed, K., Tucci, C. E. M.., \& Bidone, F. (2004). Drenagem urbana. In: Tucci, C. E. M. (Org.). Hidrologia: ciência e aplicação. (pp. 805847). Porto Alegre: ABRH. 
Research, Society and Development, v. 10, n. 16, e318101622983, 2021

(CC BY 4.0) | ISSN 2525-3409 | DOI: http://dx.doi.org/10.33448/rsd-v10i16.22983

Romão, P. A. (2006). Modelagem de terreno com base na morfometria e em sondagens geotécnicas - região de Goiânia - GO. Tese (Doutorado), Universidade de Brasília. Departamento de Engenharia Civil e Ambiental.

SCS - Soil Conservation Service. (1971). Design hydrographs, section 4, hydrology. In: MOKUS, V. National Engineering Handbook, USDA, Washington D. C.

Secretaria Municipal de Ciência, Tecnologia e Inovação. (2018). Shapefiles, arquivos em extensão kmz do Município de Goiânia. Goiânia: SECTEC.

Seibt, A. C. (2013). Modelagem hidrológica da Bacia Hidrográfica do Córrego Botafogo - Goiânia - GO. Dissertação de Mestrado, Universidade Federal de Goiás - UFG. Goiânia, Brasil.

Secretaria Municipal de Desenvolvimento Urbano Sustentável. (2020). Ortofotos do município de Goiânia, Goiás. 1992, 2001, 2006, 2011 e 2016. Goiânia: SEMDUS.

Secretaria Municipal de Planejamento e Urbanismo. (2018). Coletânea Urbanística. http://www.goiania.go.gov.br/shtml/seplam/legisla cao/legislacao.shtml\#uso

Silva, A. M., Schulz, H. E., \& Camargo, P. B. (2004). Erosão e Hidrossedimentologia em Bacias Hidrográficas. Rima

Silva, A. C S da. (2021) Análise da tendência de chuva entre 1949 e 2019 em Goiânia, GO. Dissertação de Mestrado em Agronomia, Universidade Federal de Goiás - UFG. Goiânia, Brasil.

Soares, M. R. G. J. Fiori, C. O., Silveira, C. T., \& Kaviski, E. (2017). Eficiência do método curve number de retenção de águas fluviais. Mercator, Fortaleza, 16 (e16001). https://doi.org/10.4215/rm2017.e16001.

Software Arcgis. Versão 10.3. ArcMap. ESRI - Official Distributor, portadora de direitos sobre a plataforma. Laboratório de informática da Pontifícia Universidade Católica de Goiás.

Tomaz, P. (2010). Fórmula de Manning. Cap. 50. Noções de hidrologia.

Tucci, C. E. M. (2005). Gestão de Águas Pluviais Urbanas. Ministério das Cidades. Global Water Pertneship. Banco Mundial. Unesco

Tucci, C. E. M., \& Marques, D. M. L. da M. (2001). Avaliação e controle da drenagem urbana. Ed. UFRGS

Tucci, C. E. M. (2012). Hidrologia: ciência e aplicação. (4a ed.), Associação Brasileira de Recursos Hídricos

USGS - United States Geological Survey - Serviço Geológico dos Estados Unidos. (2018). Imagens de satélite: Landsat 5 e Landsat 8. Anos: 1988, 1998, 2008 e 2018. https://www.usgs.gov/

Villela, S.M., \& Mattos, A. (1975). Hidrologia aplicada. Mc Graw-Hill do Brasil

Zaraté, H. V., \& Pantaleão, S. C. (2014). Análise da fragmentação urbana em Goiânia: o caso do Botafogo. Revista Estudos, Goiânia, 41(especial), 137-154. 10.18224/est.v41i0. 